Yuen, S.; Yaoyuneyong, G.;\& Johnson, E. (2011). Augmented reality: An overview and five directions for AR in education. Journal of Educational Technology Development and Exchange, 4(1), 119-140.

\title{
Augmented Reality: An Overview and Five Directions for $A R$ in Education
}

\author{
Steve Chi-Yin Yuen \\ National Kaohsiung Normal University \\ Gallayanee Yaoyuneyong \\ Erik Johnson \\ The University of Southern Mississippi
}

\begin{abstract}
Augmented Reality (AR) is an emerging form of experience in which the Real World $(R W)$ is enhanced by computer-generated content tied to specific locations and/or activities. Over the last several years, AR applications have become portable and widely available on mobile devices. AR is becoming visible in our audio-visual media (e.g., news, entertainment, sports) and is beginning to enter other aspects of our lives (e.g., e-commerce, travel, marketing) in tangible and exciting ways. Facilitating ubiquitous learning, AR will give learners instant access to locationspecific information compiled and provided by numerous sources (2009). Both the 2010 and 2011 Horizon Reports predict that AR will soon see widespread use on US college campuses. In preparation, this paper offers an overview of $A R$, examines recent $A R$ developments, explores the impact of $A R$ on society, and evaluates the implications of AR for learning and education.
\end{abstract}

Keywords: augmented reality, AR, education, virtual reality, mixed reality

\section{Introduction}

Augmented reality (AR) is an emerging form of experience in which the real world (RW) is enhanced by computer-generated content which is tied to specific locations and/or activities. In simple terms, AR allows digital content to be seamlessly overlaid and mixed into our perceptions of the real world. In addition to the $2 \mathrm{D}$ and $3 \mathrm{D}$ objects which many may expect, digital assets such as audio and video files, textual information, and even olfactory or tactile information can be incorporated into users' perceptions of the real world. Collectively, these augmentations can serve to aid and enhance individuals' knowledge and understanding of what is going on around them. Rather than seeming out of place, the digital markups inherent in AR lets users perceive the real world, along with 'added' data, as a single, seamless environment.

Though science fiction long ago introduced the concept of AR into our collective consciousness, until very recently, many might have labeled it a feature of our distant future. Now, however, we are riding the crest of a technological wave. AR is on the verge of becoming a household term, and perhaps, for many, an inseparable part of everyday life. 
While the technologies that make it possible have been around for quite some time, only recently has AR become "doable" on consumer grade devices. The implementation of Flashbased AR detection algorithms, together with the growing popularity of mobile platforms (e.g., iOS and Android), has at last opened the door, allowing AR to become accessible to the masses. Already AR is becoming visible in our audio-visual media (e.g., news, entertainment, sports) and is beginning to enter other aspects of our lives (e.g., e-commerce, travel, marketing) in tangible and exciting ways.

While we can easily imagine applications for AR in many fields, perhaps most exciting are the possibilities inherent for education. With AR, educators' dream of ubiquitous learning can become a reality. As never before, through AR, learners will be able to gain immediate access to a wide range of location-specific information, compiled and provided by a variety of sources. Each year, the New Media Consortium's (NMC's) Emerging Technology Initiative generates a Horizon Report which seeks to identify and understand emerging technologies which promise to have a significant impact on various sectors around the globe, and which show the potential to positively impact learning, creative inquiry, and education (NMC, 2011). Both the 2010 and 2011 Horizon Reports (NMC) have predicted that AR will see widespread use on US college campuses within the next 2 to 3 years. With that in mind, this paper offers an overview of AR, examines recent AR developments, explores the impact of AR on society, and evaluates the implications of AR for learning and education.

\section{What is Augmented Reality?}

Augmented reality (AR) refers to a wide spectrum of technologies that project computer generated materials, such as text, images, and video, onto users' perceptions of the real world. Initially, researchers defined AR in terms of spe- cific facilitating devices, such as head mounted displays (HMDs). However, arguing that such definitions were too simplistic for an evolving and expanding field, Azuma (1997) and other researchers (Kaufmann, 2003; Zhou, Duh, \& Billinghurst, 2008) defined the implementation of AR by three characteristics: (a) the combination of real-world and virtual elements, (b) which are interactive in real-time, and which (c) are registered in 3D (i.e., the display of virtual objects or information is intrinsically tied to real-world loci and orientation). Similarly, Höllerer and Feiner (2004) define AR systems as those which combine "real and computergenerated information in a real environment, interactively and in real time, and [which align] virtual objects with physical ones" (p. 2). Ludwig and Reimann (2005) define AR as "human-computer-interaction, which adds virtual objects to real senses that are provided by a video camera in real time" (p. 4). Zhou, Duh, and Billinghurst (2008) simply define AR as technology "which allows computer generated virtual imagery to exactly overlay physical objects in real time" (p. 193).

\subsection{Augmented Reality and Virtual Reality}

While considering the array of developing technologies, all seeking to modify, augment, interface with, or even replace our perceptions of reality, Milgram and Kishino (1994) sought to clarify the work being done by defining four types of environments. First is the real world, or the real environment, which we are all familiar with. On the opposite end of the scale are virtual worlds, or virtual environments (often previously labeled virtual reality), in which all information perceived by the user is computer-generated and completely unrelated to real world locations, objects, or activities. Between these two extremes exist, at least conceptually, two types of augmented environments: Augmented Reality (AR) which takes the real world and real environments as its backdrop 
and inserts computer-generated content, and augmented virtuality, in which a computergenerated world serves as the backdrop while real-world data is blended in and superim- posed. Figure 1 illustrates the mixed reality (MR) spectrum, or the Reality-Virtuality (RV) Continuum, proposed by Milgram et al. (1994).

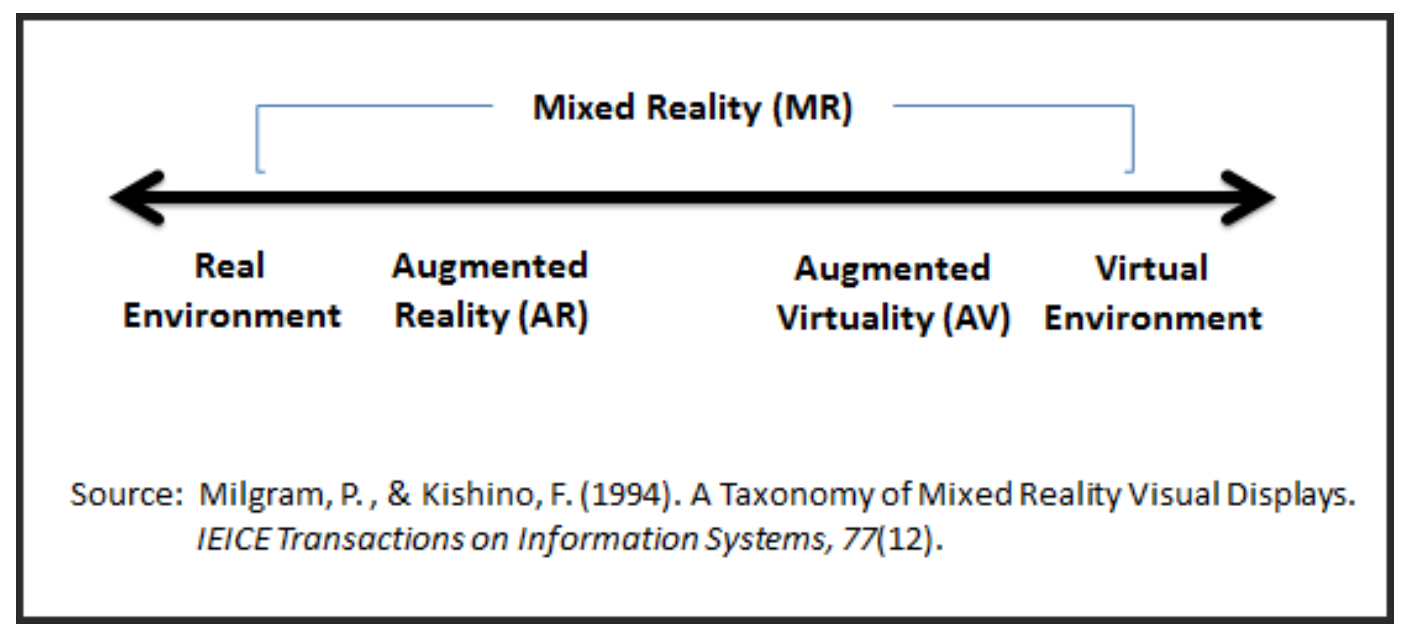

Figure 1. Reality-Virtuality (VR) Continuum

Augmented reality (AR) is closely tied to virtual reality (VR), since the concept of AR evolved as an extension, or variation, of VR (Milgram, Takemura, Utsumi, \& Kishino, 1994).

$\mathrm{AR}$ is closer to the real world on one end of the gamut with the dominate perception being the real world which is improved by digital data or assets. AV is closer to a complete immersive virtual environment involving systems that are mostly computer generated, but have some real world imagery added. Virtual environments (VE) are environments that are totally simulated by technology. As technologies continues to rapidly advance, it seems possible that the virtual elements and real world elements sharing space in mixed reality environments will become more and more difficult to tell apart.

$\mathrm{AR}$ is quite similar to virtual reality (VR). Both are interactive, immersive, and include information sensitivity. In VR, users' frame of reference is completely tied to a virtual world, whereas in AR users' perception is still cen- tered within the real world, but with virtual objects superimposed, such that real and virtual objects seem to coexist in the same space (Azuma, 1997). Second Life, by Linden Lab, is probably the best known example of VR. On the other hand, popular gaming consoles such as the Nintendo Wii, the PlayStation 3, and the Xbox 360, have all released sport-centered games, and other games, where the players' real-world movements control a virtual avatar within a virtual environment. Collectively, these are probably the best known examples of AV. Moving along in the RV Continuum, smart phone apps that utilize GPS data, or which display virtual images tied to real world locations are probably the best known examples of AR. Additionally, the gaming industry is beginning to release AR titles (e.g., Eye of Judgment and Eye Pet, by PlayStation).

\subsection{Augmented Reality Technology}

Augmented reality content can be viewed in several ways. Initially, people may have encountered web applications which let them 
view quick response $(\mathrm{QR})$ codes through their webcam. Using QR codes (markers), digital information, including 3D animations, can be attached, in a sense, to images on paper, cards, or other surfaces. When a marker is held in front of a webcam, those using AR applications through a computer or console can view digital content superimposed over their real environment (the paper in their hands), as shown by the display screen (which simply shows the room as the webcam sees it, augmented by the AR content). Usually, when the user moves or rotates the marker image, the digital content moves and rotates as well. Another viewing option is to use a head mounted display (HMD). While wearing a HMD (which covers the eyes), users can see digital content on the HMD screen and their real environment through the screen (or displayed on the screen by an attached camera).

Today, many mobile AR applications are location based. To utilize these AR applications on a mobile device or a smartphone, the phone must be equipped with several necessary tools:

(a) GPS technology; (b) an accelerometer, and

(c) a digital compass (magnetometer). Using mobile AR applications, users may view the world through smartphone cameras in order to see digital content mixed with the real environment.

\section{History and Recent Developments}

Researchers have pursued AR because it may (a) allow for the enhancement of users' perceptions, knowledge, and interaction with the real world (Azuma et al., 2001) and (b) because AR has the potential to improve productivity in real world tasks (Schmalstieg, 2001). According to Billinghurst and Henrysson (2009), the research and development necessary for current implementations of AR have gone on over the past four decades (see Figure 2). However, it wasn't until the 90s that inertia became significant, and the numbers of researchers and developers in th AR field increased. In recent years, growth and progress in AR has been significant (Phan \& Choo, 2010). Some of companies currently involved in the development of AR technologies and applications are ARToolkit, ARQuake, Google, Inglobe Technologies, Layar, metaio, nhow Berlin, Total Immersion, and Webtitude.

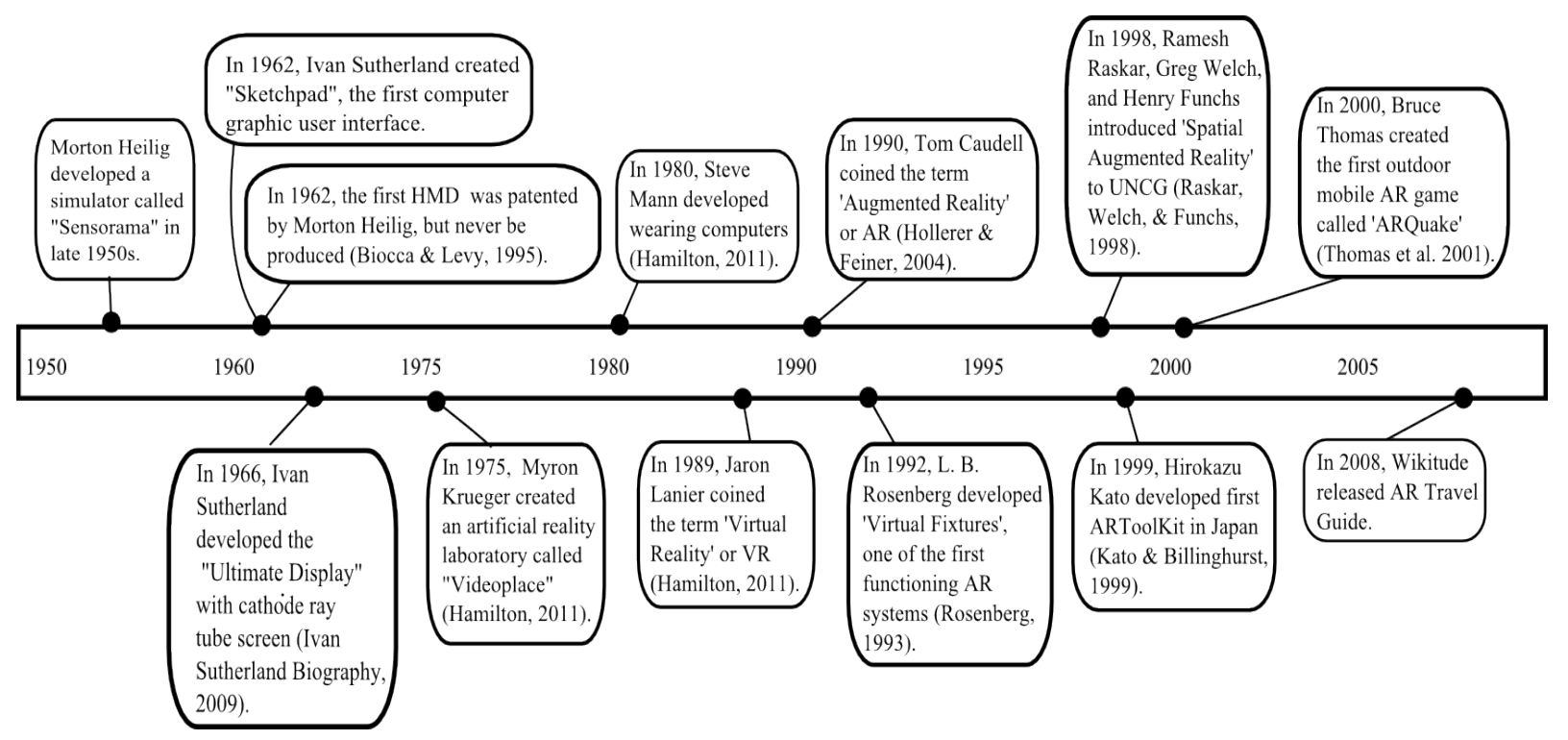

Figure 2. History of AR - a brief timeline 
AR research tends to pursue either (a) the development of new devices and technologies for the tracking, display, and input of real world and virtual data, or (b) the development of applications utilizing existing technologies (Billinghurst \& Henrysson, 2009). Zhou, Dun, and Billinghurst (2008) present a useful review of research published and presented at the AR conferences which have gone on under various names for the past ten years (e.g., ISMAR, ISAR, ISMR, and IWAR). According to Zhou, Dun, and Billinghurst (2008), AR research has focused primarily focused on five core areas essential to deliver AR applications: (a) techniques for tracking $(20.1 \%)$, (b) techniques for interaction $(14.7 \%)$, (c) calibration and registration issues $(14.1 \%)$, (d) developing AR applications (14.4\%), and (e) display techniques (11.8\%). Additionally, some researchers have also looked into newly emerging directions for AR, including: (a) evaluation and testing, (b) mobile and wearable AR platforms, (c) AR authoring, (d) visualization, (e) multimodal AR, and (f) rendering (Zhou, Dun, \& Billinghurst, 2008).

In 2008, during their Emerging Trends and Technologies Roadshow, the IT research and advisory firm, Gartner, Inc., predicted that AR would be one of the top 10 disruptive technologies for the 2008 to 2012 period (Gartner Identifies Top Ten Disruptive Technologies for 2008 to 2012, 2008). More recently, a report by Juniper Research (2011) found that the increasing focus on incorporating AR elements within mobile applications will lead to nearly 1.4 billion annual downloads of such apps worldwide by 2015, up from just over 11 million in 2010 . With today's market and consumers more focused on small mobile devices such as Android Phones and iPhones, AR development is booming, especially in the areas of marketing and entertainment (Hamilton, 2011). It was further indicated that the number of AR capable apps available had both increased dramatically, and diversified, moving beyond the initial wave of location-based search apps to include games, social networking, educational, lifestyle, and personal healthcare apps (Grabham, 2009; Juniper Research, 2011). Unsurprisingly, these developments have accompanied a surge in the deployed base of AR capable smartphones.

\section{Applications of Augmented Reality}

AR represents the cutting edge of modern society's social-technological development. AR applications are being created by independent groups and organizations all over the world for use within many disparate fields. With this being the case, despite the definitions mentioned earlier in this paper, there remains no consensus as to what constitutes true AR applications and technologies, or how the possible applications of AR should be conceptually organized. According to Azuma et al. (2001), the goal of AR is to use $3 \mathrm{D}$ virtual objects as tools to enhance users' perception of, and interaction with, the real world, by causing 3D virtual objects to appear seamlessly within the $3 \mathrm{D}$ environment of the real world. However, AR technologies can be designed to interact through many sensory channels (e.g. auditory, visual, olfactory, and haptic) which renders definitions focused only on visual data insufficient to deal with future developments in AR (Hughes, Stapleton, Hughes, \& Smith, 2005).

Ludwig and Reimann (2005) offer an organizational scheme which argues that potential AR applications fall into three main categories: (a) presentation and visualization, (b) industry, and (c) edutainment. Additionally, Hamilton (2011) offers an extensive breakdown and analysis of AR applications within education, as well as within the media and entertainment industry, the gaming industry, the travel and tourism industry, the field of marketing, the expanding field of online social networks, and in everyday life. While Hamilton (2011) and others point out that many cur- 
rent AR applications may seem gimmicky and transient, the fact remains that many of the AR applications discussed by Azuma (1997) have been refined and continue to play important parts in our modern world.

It cannot be denied that $\mathrm{AR}$ applications have tremendous potential for all fields where rapid information transfer is critical. This is especially true for education. However, around the world, the cutting edge of AR research and development is being driven more by businessrelated interests than by groups focused on augmenting education. A majority of AR technologies are being developed with no actual educational agenda. However, teachers, as always will be able to examine what is available and put it to use effectively. For this reason, we will first examine the development of AR in several non academic fields, before specifically addressing the application of AR in education.

\subsection{Advertising and Marketing}

In no other field has the AR excitement exploded in such a huge way than in advertising and marketing. Companies seeking new ways to engage and interest potential customers have implemented a variety of AR applications which present users with virtual objects, apparently sharing their space, which can be explored and manipulated using natural movements and hand-gestures. For example, cutting-edge automotive campaigns are displaying full-size AR virtual cars in shopping centers and other public areas. A markerless interface allows pedestrians, who do not need AR gloves or other controllers, to use their real-time spatial output (movements) to toggle virtual buttons, open doors, fold seats, and rotate virtual model vehicles (Yuen, 2011, February 25).

Smaller products, such as toys, can now be viewed virtually in stores and kiosks worldwide, sometimes with integrated 3D animations. Somewhat more sophisticated campaigns allow users to use their smartphones to view, rotate, and resize virtual models of products, such as furniture, anywhere in their environment, so that they can gain a more accurate impression of how the item would complement their current furnishings and decorating scheme.

Other AR applications can be conceptualized as 'marking-up people', by adding virtual clothing or apparel items which they seem to 'wear'. Prominent examples of this can be seen in the kiosks, 'virtual dressing rooms' and 'virtual mirrors' of companies selling designer accessories such as sun-glasses or watches. These applications are being utilized by corporations to enrich customer shopping experiences, both in real-world and in online retail venues. Shoppers are able to share their choices, or 'likes' through social media, and are often able to make their final purchase through the AR interface.

In a third category of AR marketing applications, real-world objects are 'marked-up' with superimposed, but conceptually unrelated 3D artifacts. Utilizing this strategy, a one company has created a series of AR games in which consumers use actual shoes, in conjunction with a computer and a webcam, to play AR games whose environments seem to pop out of the shoes themselves. Fast-Food and Media companies have utilized AR technology to cause popular 3D characters to spring out of soft-drink cups, and other packaging in fast-food franchises (Hampp, 2009). A similar application of technology is being used for a more utilitarian purpose by the U.S. Postal Service, which allows users to view holographic boxes, projected from any sheet of paper with the appropriate QR Code. This allows customers to compare the size of the items they wish to ship to the size of the virtual box visible on their screen. 


\subsection{Architecture and Construction}

According to Behzadan (2008), AR systems can be used to allow designers, workers, customers and potential employers to actually walk through a real world site and visualize and experience a virtual facility or building under construction or planned for the future. The technology could also help in the planning of construction jobs by allowing workers to see visual representations of underground utility lines or pipes. Electricians and other professionals that are working together on a job would be able to cohesively view how things should be wired, or where other equipment, pipes, and the like are supposed to be placed. All of the data would come from a 3D model and associated digital information about the structure. In short, there are numerous ways where the use of AR technology can save time and money, as well as reduce problems, in the field of architecture and construction.

\subsection{Entertainment}

Blurring the mixed reality continuum, Hatsune Miku, a completely virtual singer, has given live concerts in Japan, as a hologram requiring no special equipment for the audience to perceive. Using more conventional AR technology, in the book industry AR books have been released featuring animated images, overlaying and interacting with the pages of the book, and accompanied by music and sound effects (Billinghurst, Kato, \& Poupyrev, 2001). Another approach involves AR 'popup' books, in which still or animated 3D images hover over the pages of the book, often accompanied by sound (Billinghurst, Kato, \& Poupyrev, 2001). Meanwhile, development in markerless AR tracking is facilitating the creation of more traditional board games, such as Monopoly, in a virtual format.

The electronic games industry and the social media industry are both broadening their scope to include AR technologies. Smartphone apps now allow users to fire AR Gatling guns which appear to actually hit real-world objects. Smartphone apps and hand-held game consoles have released games which let users track and collect virtual fairies and other mythological creatures which appear in the real-world landscape around them (Lewis, 2005). According to Raju (2009), AR games of these sorts are notable for providing stress relief.

Companies have enabled various complex AR entertainment projects through the iPad, such as a holographic helicopter which hovers over the surface of the iPad screen (Yuen, 2011, February 19). Other apps allow users to fly an actual Remote Controlled (RC) helicopter (or drone) using a smartphone or other mobile device as the control and interface. These drones are equipped with cameras which allow AR games, such as virtual obstacles overlaid over the real-world environment, or dog-fighting with virtual (or real opponents), using virtual weapons (Webster, 2009).

\subsection{Medical}

According to Samset et al. (2008), AR technology will not only be able to enhance medical surgical and clinical procedures by improving cost effectiveness, safety, and efficiency, medical AR systems may also assist in the invention of new surgical procedures. AR systems have potential to support surgeons with navigation and orientation before, during, and after surgery. Medical AR applications will allow for more advanced pre-operative imaging studies, letting doctors and surgeons examine a holographic view of patients' internal anatomy compiled from CT, MRI, and ultrasound data. After a surgical procedure has been planned, AR systems can use streaming input data to create virtual superimposed images in realtime. Beyond visual augmentation, AR systems can integrate haptic devices (touch, or vibration feedback tools) to let surgeons feel tumors, 
or otherwise explore the patient's condition via touch, without having to perform open surgery. Furthermore, an AR system combined with dependable and consistent force feedback could make more difficult surgeries eventually become minimally invasive (Samset et al., 2008).

\subsection{Military}

A well-known military AR application involves the HMDs, worn by fighter and helicopter pilots, which allow users to view relevant information such as instructions, maps, and enemy locations (Sisodiaa et al. May, 2007). This information can also be displayed on a vehicle screen, or even on the windshield of a cockpit. For soldiers on the ground, as well as in the air, military-grade AR helmets are in development, to be equipped with computers, 360-degree cameras, UV and infrared sensors, stereoscopic cameras, and OLED translucent display goggles. Wearing AR helmets, soldiers will be able to communicate with a massive "home base" server that collects and renders 3D information onto the wearers' goggles in real time. Various objects and people will be outlined in specific colors to warn soldiers of friendly forces, potential danger spots, impending air-raid locations, rendezvous points, and other critical data. With the full deployment of AR technology, the face of military combat may be changed beyond recognition (Sisodiaa et al. May, 2007).

\subsection{Travel}

Even for non-combatants, AR can be used to enhance users' experience navigating in the real-world. Civilians are already accustomed to using onboard GPS systems while driving, and to using online search apps to find locations and services they are looking for. Additionally, civilians are growing used to social media, which uses data about people's realtime, real-world locations to drive interaction and interest in activities. With AR, these services will become visible, as virtual holo- graphic signs, markers, guiding lines, floating arrows, and other cues. Beyond the simple sensory expansion of these existing services, AR can lead to newer, more comprehensive interfaces showing users tourist (social-historical) and business (locations, services) information relevant to the area surrounding their real-world location, simply by checking with the user's smart-phone GPS, or when queried via a quick snapshot with the smart-phone's camera. Additionally, auto manufacturers have plans underway to make cars into mobile devices complete with built in monitors, integrated wireless or satellite internet, and AR windows giving infrared and ultraviolet sensing, and virtual-holographic markup of the surrounding real-world environment, similar to the interfaces available in some high tech military aircraft (Carr, 2011; Dugdale, 2010).

Until smart-cars come to pass, available informatory smart-phone AR applications have been developed which expand users' experience by supplying additional data based on their real-world location (Raju, 2009). Users can search online for the significance of images viewed through their smartphones, and can access a variety of location-specific data, such as Tweets from physically nearby individuals, location-specific historical and triva information (wikitude.org), directions back to their parked car, prices in nearby gas stations, or directions to the most convenient subway (Raju, 2009).

\section{Augmented Reality in Education}

Given the exciting developments and the manifest functionality of AR as an improved user interface technology, researchers believe that AR has vast potential implications and numerous benefits for the augmentation of teaching and learning environments (Billinghurst, 2002; Cooperstock, 2001; Klopfer \& Squire, 2008; Shelton \& Hedley, 2002). For example, AR has potential to: (a) engage, stimulate, and motivate students to explore class materi- 
als from different angles (Kerawalla, Luckin, Selijefot, \& Woolard, 2006); (b) help teach subjects where students could not feasibly gain real-world first-hand experience (e.g. astronomy and geography) (Shelton \& Hedley, 2002); (c) enhance collaboration between students and instructors and among students (Billinghurst, 2002); (d) foster student creativity and imagination (Klopfer \& Yoon, 2004); (e) help students take control of their learning at their own pace and on their own path (Hamilton \& Olenewa, 2010), and (f) create an authentic learning environment suitable to various learning styles (Classroom Learning with AR, 2010).

Researchers have explored the use of AR applications within a variety of fields and disciplines, many of which are already directly or indirectly related to education. For example, Liu, Jenkins, Sanderson, Fabian, and Russell (2010) have examined medical applications of AR in general anesthesia. Similarly, Sielhorst, Obst, Burgkart, Riener, and Navab (2004) have looked at the use of AR for medical training simulations. Also, Sielhorst, Feuerstein, and Navab (2008) have reviewed the 1990s AR medical display literature extensively. Other researchers (Liarokapis et al., 2004) have examined the use of AR as a tool for engineering where Web3D and AR technologies allow students to explore mechanical engineering concepts. Kaufmann and his team have focused their AR research on applications in mathematics and geometry by creating an AR system to facilitate learning between instructors and students (Kaufmann, 2003; Kaufmann \& Dünser, 2007; Kaufmann \& Schmalstieg, 2003). Additionally, researchers have investigated the feasibility of various AR applications for use within the field of e-commerce (Zhu, Owen, Li, \& Lee, 2004), e-learning systems (Cho, Lee, Soh, Lee, \& Yang, 2007; Liarokapis,Petridis, Lister, \& White, 2002), architecture (Billinghurst \& Henrysson, 2009; Thomas et al., 2001), interior design (Phan \& Choo, 2010), and science education (Kerawalla, Luckin, Selijefot, \& Woolard, 2006; Shelton \& Hedley, 2002). The remainder of this paper examines five significant educational applications of AR technology: AR books, AR gaming, discovery-based learning, objects modeling, and skills training.

\subsection{AR Books}

It is likely that AR books will be a major stepping stone helping the public bridge the gap between the digital and physical world. AR technology has great potential to offer students $3 \mathrm{D}$ presentations and interactive experiences that are likely to appeal to digital native learners. For instance, an AR book entitled "The Future is Wild: The Living Book" was developed by Meatio in Germany and was launched at the Frankfurt Book Fair in 2011. The book, with 42 integrated $\mathrm{AR}$ special features, demonstrates the potential of AR to encourage readers to build a connection to a book (Yuen, 2010, November 19). Another type of AR book experience is offered by AR pop-up books (Digilog Books), created by Gwangju Institute of Science and Technology (GIST) in South Korea, which can display 3D characters spring from each page when readers wear a special pair of glasses. The AR system works in real-time with 30 fps and supports about 300 pages without losing real-time performance (Yuen, 2010, November 19).

In addition, AR books can be used at the primary level. The Institute for the Promotion of Teaching Science and Technology in Thailand developed a 3D augmented reality geology textbook which teaches students about the discovery of earth's layers, their relationships, differences, and functions (Yuen, 2010, November 19). Also, MagicBook, an AR interface system, allows AR content to be created for any normal book, bringing the book to life with animated and even interactive models drawn from the text or illustrations already in the book (Billingurst, 2002). Students are able 
to use the book as the primary interface, changing perspective or direction by moving (their head), or by moving the book, because the 3D computer-generated content appears to be attached to the book page. In our society, where critics of conventional literature have begun to become uncomfortably aware that even video games can be stories, AR books will open the art of fiction and storytelling to an entirely new interface, demanding greater attention from the 'authors' to a variety of issues, such as the books cohesion, quality on many fronts, and immersiveness. However, the potential of AR books to appeal to many types of learners, through many paths, is undeniable, and exciting for educators.

\subsection{AR Gaming}

Often educators utilize games to assist students in easily grasping class concepts. With the help of AR technology, games that are based in the real world and augmented with networked data can give educators powerful new ways to show relationships and connections. Games using marker technology often include a flat game board or map which becomes a 3D setting when viewed with a mobile device or a webcam. This kind of game could easily be applied to a range of disciplines, including archaeology, history, anthropology, or geography, to name a few. Another approach to AR gaming allows players or game masters to create virtual people and objects, and then to tie these constructs to specific locations in the real world. Players can then interact with these digital creatures and objects, which appear when the player approaches the pertinent linked location in the real world.

AR games present educators with the opportunity to utilize a new highly visual and highly interactive form of learning. As an example, SimSnails is an interactive visualization and teaching tool that helps visitors learn about, and experiment with, the concepts of natural selection and evolution. Using AR technology, SimSnails uses a set of printed symbols and a video camera to create an immersive 3D world that seamlessly coexists with our own perceived real-world environment (http://www. youtube.com/watch?v=4JTCabfxEcw).

A recent study explored some of the possibilities of AR gaming for education. An AR video game called Alien Contact was used in several K-12 classes in an effort to increase student learning and engagement (Handheld Augmented Reality Project \& Alien Contact, n.d.). As a team, students each played different roles and used a handheld device, which incorporated GPS technology, a compass, and wireless internet. The objective of the game was to discover why aliens had come to earth and landed in a particular area. The students were guided to form a hypothesis by collecting evidence and successfully completing problems, necessitation the use of proficient math, science, and language arts skills. Participating in the game, the students interacted with digitally simulated game characters, digital items, and their group members to plot a course through the game space to reach the intended final objective.

Unfortunately, Alien Contact had some disadvantages in an educational setting, mainly due to hardware and software problems. Teachers reported trouble managing student groups while dealing with problems and while trying to keep to the lesson plan. Also, several students experienced cognitive overload when trying to learn the new technology while also attempting to answer the game questions in a timely manner. Additionally, some instances of students being so occupied by their handheld screens that they totally lost track of their actual surroundings were recorded. While the game was intended to hold the attention of the learner, a student being oblivious to the environment around them is a safety hazard risk (Dunleavy, Dede, \& Mitchell, 2009). Despite these difficulties, it must be remembered that 
AR gaming is still in its infancy. As designers gain more experience and as design flaws in the user interface are ironed out, AR gaming holds the potential to be a tremendously effective tool for gaining students' interest and attention while teaching a variety of skills.

\subsection{Discovery-based Learning}

AR Applications that convey information about a real-world place open the door for discovery-based learning. Currently, many historic sites supply overlay maps and different points of historic information for their visitors. However, in the near future, AR will bring even more excitement into historic sites though various developing projects. For example, the EU-funded iTacitus AR project (www.itacitus. org) will allow visitors to pan across a location while hearing and seeing a historic event play out. Another AR tool, the TAT Augmented ID application, will use facial recognition technology to display certain, pre-approved information about a person when s/he is viewed through the camera of a mobile device. A third tool, SREngine, will use AR object recognition to display information about everyday items in the real world, allowing for easy price comparison while shopping, as well as identifying plants and animals.

Wikitude and similar mobile applications could transform school field trips by replacing paper question sheets with just-in-time information access (activated by learners' smart phones' GPS when they encounter items of interest). Wikitude can provide students with up-to-the minute information on locations, concepts, and sites. Field trips could turn into virtual scavenger hunts with specific information or code gathered from different locations. Constructivist teachers can assign students research collaboration projects and create content relevant to the areas, events, and concepts studied in their field trips. Also, gathered, compiled, or created information can be made available publicly, so anyone using a compatible mobile app could access the information when they visit the same sites. In this respect, students would not only take knowledge away with their field trips, but they would leave new knowledge behind for future visitors (De Lorenzo, 2009).

Another application, LearnAR (www.learnar.org), uses AR technology to bring investigative, interactive and independent learning to life by superimposing a 3D image over a particular marker shape. LearnAR created a pack of ten curriculum resources and learning activities in various subjects, such as biology, chemistry, English, math, physics, foreign languages, and physical education, for teachers and students to explore by using a webcam. These AR activities allow independent investigation of scenarios (e.g. chemical reactions, learning about Sikhism, and exploring 3D geometric shapes). LearnAR offers flexible learning, which means it can be used in class by teachers and students, or at home by students exploring the subjects independently.

\subsection{Objects Modeling}

Augmented reality can also be used to model objects, allowing learners to envision how a given item would look in different settings. Models can be generated rapidly, manipulated, and rotated. Students receive immediate visual feedback about their ideas and designs in a way that allows them to spot inconsistencies that need to be addressed. Researchers in the Human Interface Technology Laboratory at the University of Canterbury in New Zealand have created a tool that translates sketches into $3 \mathrm{D}$ objects and uses augmented reality to allow students to explore the physical properties and interactions between objects. Simple controls, drawn on slips of paper, are used to alter the properties of the sketched objects. At Mauricio De Nassau College in Brazil, architecture students are exploring the possibilities of using 
augmented reality to project scale models of buildings, cutting down on the time required to construct and present architectural proposals.

\subsection{Skills Training}

Another educational function where AR will shine is in the area of skills training. Augmented reality has strong potential to provide powerful contextual, in situ_learning experiences and serendipitous exploration while simultaneously promoting the discovery of the connected nature of information in the real world. AR goggles have already been used to train individuals, especially in specific tasks, such as hardware mechanics in the military, or airplane maintenance, at companies such as Boeing. The AR goggles are able to display each step in a repair, identify the tools needed, and include textual instructions. Examples of a similar AR teaching technology is a medical program developed by the University of North Carolina at Chapel Hill for physicians training and practicing ultrasounds on pregnant women. With the ultrasound information, the program projects the inside of the woman's womb onto the doctor's glasses. In a less hazardous but also needed area, Columbia University has created an Augmented Reality program for visual printer-repair manuals (Azuma, 1997).

In another military example, developers at Columbia University's Computer Graphics and User Interface Lab have created an AR system called ARMAR that guides military mechanics in conducting routine maintenance and repair tasks inside an armored vehicle turret. ARMAR is a head mounted display unit that provides graphic overlays to assist mechanics in making repairs. Any Android phone provides an interface to control the graphics mechanics view during the process. A within-subject controlled user study examined professional military mechanics using our system to complete 18 common tasks under field conditions. These tasks included installing and removing fasten- ers and indicator lights, and connecting cables, all within the cramped interior of an armored personnel carrier turret. An augmented reality condition was tested against two baseline conditions: an untracked head-worn display with text and graphics and a fixed flat panel display representing an improved version of the laptopbased documentation currently employed in practice. The augmented reality condition allowed mechanics to locate tasks more quickly than when using either baseline, and in some instances, resulted in less overall head movement. A qualitative survey showed mechanics found the augmented reality condition intuitive and satisfying for the tested sequence of tasks (Saenz, 2010, January 11).

\section{Tools for Augmented Reality Applications}

Depending on the type of augmented reality being planned for and the devices available for students to utilize the AR, many tools are now available for educators wishing to create augmented reality applications in education. In the hopes of spurring experimentation, some of the more useful tools will be discussed.

Some tools, such as Daqri, MixAR, and ZooBrust, are quite simple and require no programming knowledge or skill. Others tools include SDK kits such as ARToolKit, Unifeye Mobile SDK, and Wikitude, which have been developed for serious AR developers. These kits are very powerful and allow developers design various AR applications for variety of devices. Unfortunately, the more advanced tools require extensive knowledge and experience in computer programming, Java, and 3D virtual reality.

Daqri (www.daqri.com) is a content publishing platform that allows users to create $\mathrm{QR}$ codes that display images, movies, and other pieces of content as soon as they are viewed through a smartphone camera. Daqri overlays $3 \mathrm{D}$ images onto the real world through an 
iPhone or an Android device, using QR codes as the anchor. The best part is that Daqri will enable users to create augmented reality products without writing any code. Daqri launched in February 2011 and is currently still in private beta (Yuen, 2011, July 14).

Hololabs studio is currently developing an application for iPhone named MixAR, which allows the user to create custom 3D AR models, photos or videos without any requirement of coding. MixAR is basically an AR editor, as its platform enables users to photograph an object, then converts it into a 3D model which can be overlaid in AR and recorded as video and share it with the world. All this can be done using just an iPhone. At the time of the writing, MixAR is not yet available to the public (Gordon, 2011, February 2).

ZooBurst (www.zooburst.com) is a 3D storytelling tool for authors easily create their own 3D pop-up books. Authors can choose one of the books on the Web site, then simply hold the ZooBurst marker in front of their Webcam. A 3D pop-up book will magically appear on the screen, zooming out from the piece of paper. The on-screen book is entirely interactive, allowing readers to change the page, click on characters to see dialogue, or tilt the paper in any direction to view the story from a different angle. Authors can arrange characters and props within a 3D world that can be customized using uploaded artwork or items found in a built-in database. In addition, authors can also record their own voices using the ZooBurst audio recorder to have their characters speak to the readers (Carr, 2010, May 11).

ARToolKit is a free, open-source, C language software library for creating AR applications. ARToolkit was originally created by Hirokazu Kato in 1999 and its ongoing development is being supported by the Human Interface Technology Laboratory (HIT Lab) at the University of Washington, HIT Lab NZ at the
University of Canterbury, and ARToolworks, Inc. ARToolKit uses computer vision techniques to calculate the real camera position and orientation relative to marked cards, allowing the programmer to overlay virtual objects onto these cards. Many AR projects have been made with the ARToolKits, including 3D-Live, AR Groove, FaiMR, MagicBook, and PyARTK (Billinghurst, Kato, \& Poupyrev, 2001).

Metaio has developed the Unifeye Mobile SDK that allows developers to create AR applications for iPhone, Android, Symbian, and WinMobile devices. The Unifeye Mobile SDK is a comprehensive mobile AR software suite that allows developers to take advantage of the Unifeye platform applications including its configuration templates, 2D texture/image tracking, 3D object tracking, marker tracking, GPS tracking plug-ins, video support and webbased rendering engine (Metaio, 2011).

Wikitude offers powerful APIs to add AR content to Wikitude World Browser. The APIs suite is a powerful application programming interface that allows for the open development of markerless AR experiences, providing developers with the tools to create their own mobile AR applications (Wikitude, n.d.).

Other AR SDK kits includes: (1) AllJoyn SDK (https://www.alljoyn.org/docs-and-downloads) allows developers to create viral and social apps with connectivity across devices via ad hoc, peer networks. (2) Brew MP SDK (https:// developer.brewmp.com/tools/brew-mp-sdk) introduces a fully-integrated development environment and expands the platform to Flash and JAVA developers. (3) Adreno SDK (http:// developer.qualcomm.com/dev/gpu) provides multi-platform graphics optimization tools. (4) Qualcom QCAR SDK (https://ar.qualcomm.at/ qdevnet/sdk) provides developers the ability to create high-performance Android applications with C++ APIs. (5) Qualcomm's Gobi 2000 SDK (http://developer.qualcomm.com/ 
dev/connectivity) includes a common set of C/ $\mathrm{C}++$ APIs for developing connection managers, GPS apps, and/or manageability solutions on wireless $3 \mathrm{G} / 4 \mathrm{G}$ devices.

\section{The Future of Augmented Reality and Education}

It has long been recognized that the rapidly changing nature of modern information technologies are dramatically altering the situation of both teachers and learners. Dede (2008) points out that, as our information technologies transform, educators continuously develop new methods of teaching and learning. However, along with these changes, the characteristics of learners continuously evolve, as do the sets of skills and the areas of expertise and knowledge valued by society (Dede, 2008). Augmented reality is all around us today. The affordability of mobile devices and other hardware capable of processing and displaying information at rapid speeds has made the widespread use of AR reasonable. Furthermore, industry experts have predicted that the evolution of handheld devices, capable of delivering AR content and experiences will continue to escalate (Dede, 2008). As the tools facilitating AR continue to evolve, research and development on the applications of AR in education continue as well. Whether or not we, as educators, are ready, according to the 2011 Horizon Report, the use of simple AR in education will be widespread within 2 to 3 years across US college campuses.

However, Augmented Reality has already demonstrated several areas where it has had a positive impact on education. There are numerous fields in which AR has already shown the potential to bring about sweeping improvements. For one thing, the combination of AR simulations and training exercises, combined with tactile feedback interfaces, have been shown to improve individuals' performance in learning a variety of physical skills (Dede et al., 2009; Saenz, 2010), from delicate surgical operations to the operation and maintenance of tanks. While the process of creating AR educational materials for high-level tasks, such as surgery, relies on the skilled combined effort of multiple specialists, as each 'lesson' is created, encoded, and made available, it becomes a permanent and perpetually re-usable resource. The same benefit holds true for simpler AR lessons, games, and educational activities, designed and implemented by smaller teams of motivated, but perhaps less-funded educators. As educators experiment with available AR tools and technologies, devising different activities and ways of teaching, learning, interacting, and guiding learner exploration, permanent progress is made.

On another front, according to Billinghurst, Kato, and Poupyrev (2001), AR books can provide a critical pathway for learners, since, with AR gear, users can experience three levels of reality while using interactive AR story books. First, as a simple book, multiple users can cooperate and interact while holding and utilizing the physical object itself. Secondly, AR popup books allow multiple users to view $3 \mathrm{D}$, and perhaps animated, added AR content. Thirdly, with AR gear, users of an AR book can 'fly' or 'teleport' down into the 3D environment created by the book, and actually participate in the story as it unfolds, interacting with virtual objects, characters, or even other 'readers'. When this occurs, users have transitioned from existing within a real-world environment, to acting within a virtually-augmented real-world environment, and finally to being fully immersed in an interactive and entirely virtual environment.

According to Dede (2008), immersion of this sort, possible through AR educational activities, can be critical in supplying modern learners with an up-to-date, $21^{\text {st }}$ century education which prepares them for the challenges and activities they will face in our current, rapidly changing and technology-enhanced world. For example, modern learners need to 
learn to solve problems as part of an interactive and distributed team, in preparation for facing challenges in their future careers which actually are too big to be solved, or perhaps even conceptualized, by individuals acting alone. Dede (2008) further points out that learners need to learn to 'find' or 'define' problems, before they leap forward to 'solve' the problem. To do this, more awareness: of self, of others, and of situations, environments, possible futures, and possible outcomes and effects is necessary. According to Dede (2008), modern learners must acquire the skills associated with self-guided and group reflection. Additionally, to succeed in the tasks which they will face, which, for educators, may grow continuously harder to predict or imagine, learners must become more adept at making meaning out of complex reality. Dede (2008) lists necessary skills for modern learners, such as creating, and making use of sophisticated models, representations, and tools, noticing and identifying patterns, reasonably communicating with others who hold different perspectives, and being able to dispassionately judge the values of different viewpoints.

According to Dede (2008), all these skills can be effectively learned by users participating in interactive and immersive AR and VR educational activities. For one, through learning to adopt virtual personas, while participating in virtual tasks, problems, and games, learners can disassociate themselves from negative self-conceptions and blocks that might otherwise hinder their learning (Steinkuehler, \& Williams, 2006). Dede (2008) points out that immersive experiences, especially those in which users act out shifts in identity, can help learners achieve greater awareness of multiple perspectives. Furthermore, through the situated learning implicit in AR and VR problem solving games and exercises, learners show increased ability to transfer what they 'know' into different situations, both in AR and VR games and in their actual real-life experiences (Dede, 2008).

Beyond designed educational AR Games, such as "Alien Landing" (Dede, 2008), researchers are examining how to use game mechanics to build user interests in factual data, such as real-world socio-economic regional statistics (Diakopoulos, Kivran-Swaine, \& Naaman, 2011). With the continued development of AR educational books, and games, combined with the location-specific AR markup of the real world, such as is being done by the Philadelphia History project (http://www. prweb.com/releases/2011/5/prweb8416629. $\mathrm{htm})$, AR has the potential to make ubiquitous learning a reality, allowing learners to gain immediate access to a wide range of location-specific information from a wide range of sources.

Although AR is not new, it is still in infancy, especially regarding its educational applications. There are still many problems to overcome and issues to explore in order to optimize existing AR applications and technologies for use in education. Currently, though it is new and captivating, AR content is still quite difficult to create and deploy. For many teachers and students, the task of creating 3D models for $\mathrm{AR}$ is too difficult, since it requires significant technical knowledge. However, easier-to-use development kits are the goal of many firms investing in AR, so these problems should ease with time. For the present, educators and researchers should continue to keep up with the development of AR technology, closely monitor the impact of AR on society, consciously evaluate the implications of AR for education, and continuously explore, seeking to determine how AR can best be applied to expand our teaching and learning environments.

However, while many of the educational potentials of AR may seem exciting, some of the changes that will soon come to pass may challenge current educators' entire perception 
of academic learning and culture. For example, with the development of AR holographic projection technologies, interfaced with portable video conferencing technologies, learners and educators will soon gain the opportunity to conference face-to-face, through a portable 3D AR interface (Billinghurst, Cheok, Prince, \& Kato, 2002; Billinghurst \& Kato, 2002). With functional 3D AR conferencing, suddenly, as never before, learners and educators, will be able to communicate effortlessly over a distance, maintaining the use of the non-verbal information that is so integral to human communication.

There has already been a trend in universities around the world to shift students away from real-world classes and towards hybrid real-world/online classes, as well as towards distance-learning, or online classes. However, current, non-AR methods of online interaction, such as email, text, audio, and visual chat, shared documents and whiteboards, and other conventional internet communication protocols, all suffer to varying degrees from barriers and limitations inherent in each interface (Galusha, 1997). For this reason, both educators and learners can often approach hybrid and online learning environments with, if not apprehension, then a decided lack of optimistic enthusiasm.

However, with shared AR conferencing, delivered in full 3D at 30 frames per second (or faster), combined with shared AR workspaces, existing barriers to long-distance communication will dramatically decrease, and perhaps fade away entirely (Billinghurst, Cheok, Prince, \& Kato, 2002; Billinghurst \& Kato, 2002). While, in the short term, this would simply alleviate the stress of many students and teachers currently utilizing communication interfaces that are often described as alienating, frustrating, and plagued by technical difficulties (Galusha, 1997), the long-term consequences for teaching and learning, and in fact for educa- tional institutions as they currently exist, may be profound.

Consider, without the existing technical and ease-of-use barriers to distance communication, what will remain to cause distance-learning, and distance-instruction, to be viewed as less-desirable than face-to-face instruction? In fact, with effortless and lossless long-distance conferencing, in full, animated, color 3D, distance-learning may become difficult to distinguish from face-to-face instruction. The consequences of this for learning, as currently organized, around institutions firmly located in the real-world, may be somewhat frightening to contemplate, even as the potential for greater communication is equally staggering. Will physical schools and universities remain necessary? Will economic forces and the simple desire to continuously cut expenses, especially in the face of feasible alternatives, gradually push the physical classroom out of the real world? This is a question that cannot be readily answered beforehand, but, whatever happens, we can be sure that educators will be closely invested in the process. With the possibilities inherent in this aspect of AR technology alone, the entire face of education, and current teacher-learner interactions, will undoubtedly undergo significant transformation.

Additionally, there remains to consider the opportunity AR offers for learners to undergo unique, customized, personalized learning experiences. Rather than learning through interaction with a teacher and classmates, many individuals may find that it is more efficient, less stressful, or otherwise preferable to utilize AR learning modules independently, at whatever pace they wish, in whatever order they wish. While many current AR educational projects have focused scientific inquiry (e.g. astronomy, mathematic, architecture, and engineering), educators are even now working on AR projects designed to focus on fields such as such as language, art, political science, sport manage- 
ment, textiles, fashion merchandising, and food and nutrition. AR learning tools allow students access to capabilities and resources that can dramatically increase the effectiveness of individual study. For example, a student who wants to learn a foreign language can use AR simulations to picture where to place tongue in order to mimic correct pronunciation. With a wellprogrammed virtual instructor, there might soon be no need to ever speak to an actual human being to 'perfectly' learn a new language, or, theoretically, any other skill. With AR technologies becoming more and more integrated into individual's non-academic lives, through mobile devices and AR real-world markup (AR RWM), making available location-specific data, such as historical information, current social tweets, and real-time hazard data, the idea of 'learning' through an AR interface will eventually, and perhaps quickly, become something that is taken completely for granted.

In addition, through the continuing research in AR technologies, it is possible that AR will eventually lead to a complete and immersive VR (virtual reality), allowing humans to surround themselves with a convincing virtual environment in which they can interact with other humans, with computers, and with programs. The first steps towards this 3D internet can be seen in services like Second Life, by Linden Lab, which already has between 1 and 6 million users, depending on who's counting (Fulton, 2007). Second Life is already being utilized by universities to host virtual classrooms. With continuing advances in AR, these classrooms can be even more immersive, and 'field trips' can become spectacular and truly inspiring for students. Also, with improved AR and VR technology, virtual scenario training, for doctors, lawyers, political speakers, emergency response workers, soldiers, pilots, and in fact people of any profession or practice, including teachers, could become an incredibly valuable tool.
For the present, while movements towards increased and improved distance education, both through real-world, AR, and VR interfaces are underway and seemingly speeding along, the incredible rapidity of technological change and development is a wave that educators have grown used to riding. While the world is undoubtedly changing, we will grow and adapt along with it. In fact, if we have our way, we will be the ones on the forefront, pushing forward with new innovations and improvements for teaching and learning. On a calmer note, most current educators will find that, while it is possible for them, as individuals, to create AR content using the tools mentioned earlier in this paper, truly user-friendly AR creation tools may still be just over the horizon. With that in mind, our task remains to keep examining what is available, and creatively utilizing it, to keep driving change forward.

\section{References}

Azuma, R. T. (1997, August). A survey of augmented reality. In Presence: Teleperators and Virtual Environments, 6(4), 355-385.

Azuma, R., Baillot, Y., Behringer, R., Feiner, S., Julier, S., \& MacIntyre, B. (2001). Recent advances in augmented reality. Computers \& Graphics, 1-15.

Behzadan, A. H. (2008). ARVISCOPE georeferenced visualization of dynamic construction processes in three-dimensional outdoor augmented reality. Department of Civil and Environmental Engineering, The University of Michigan. Doctor of Philosophy: 282.

Billinghurst, M. (2002). Augmented Reality in Education. New Horizons for Learning, December 2002. Retrieved July 20, 2010 from http://www.newhorizons.org/ strategies/technology/billinghurst.htm 
Billinghurst, M., Cheok, A., Prince, S., and Kato, H. (2002). Real world teleconferencing. IEEE Computer Graphics and Applications, 22(6), 11-13.

Billinghurst, M., and Kato, H. (2002). Collaborative augmented reality. Communications of the ACM, 45(7), 64-70.

Billinghurst, M., Kato, H., \& Poupyrev, I. (2001). The MagicBook: A Transitional AR Interface. Computers and Graphics, November 2001, 745-753.

Billinghurst, M., \& Henrysson, A. (2009). Mobile architectural augmented reality. (X. Wang, \& M. Schnabel, Eds.) Mixed Reality In Architecture, Design And Construction, 3, 93-104.

Biocca, F., \& Levy, M. (1995) Communication In The Age of Virtual Reality, Lawrence Erlbaum.

Carr, A. (March 31, 2011). BMW to Launch NYC Tech Incubator with \$100 million investment fund. Retrieved July 30, 2011 from http://www.fastcompany.com/1743933/ bmw-to-launch-nyc-tech-incubator-with100-million-investment-fund

Carr, A. (2010, February 11). ZooBurst: Augmented Reality 3-D Pop-up Books for Students and Teachers. Retrieved July 22, 2011 from http://www.fastcompany. com/1644265/zooburst-augmented-reality-3-d-pop-up-books-for-students-andteachers

Cho, K., Lee, J., Soh, J., Lee, J., \& Yang, H. S. (2007). A realisitc e-learning system based on mixed reality. Proc 13th Intl Conference on Virtual System and Multimedia (pp. 5764). VSMM.

Classroom Learning with AR (2010). Trends in EdTech wiki. Retrieved July 25, 2010 from http://augreality.pbworks.com/ClassroomLearning-with-AR

Cooperstock, J. R. (2001). The classroom of the future: Enhancing education through augmented reality. Proceedings of HCI International, (pp. 688-692).
Dede, C. (Speaker). (2008). Immersive interfaces for learning: Opportunities and perils [motion picture]. (Available from The President and Fellows of Harvard College). http://cyber.law.harvard.edu/interactive/ events/luncheon/2008/12/dede

Dede, C., et al. (2009). Immersive interfaces for engagement and learning. Science, 323, 66-68. DOI: 10.1126/science.1167311

De Lorenzo, R. (2009). Augmented Reality and On-Demand Learning. The Mobile Learner. Retrieved July 22, 2010 from http://themobilelearner.wordpress.com/2009/10/17/ augmented-reality-and-on-demand-learning/

Dugdale, A. (March 17, 2010). GM to use augmented reality tech for safer driving. Retrieved July 30, 2011 from http://www. fastcompany.com/1586608/gm-to-use-augmented-reality-tech-for-safer-driving

Dunleavy, M., Dede, C., \& Mitchell, R. (2009, February 1). Affordances and limitations of immersive participatory augmented reality simulations for teaching and learning. Journal of Science Education and Technology, 18(1), 7-22.

Fulton, S. III. (May 7, 2007). How Many Users Does Second Life Really Have? Retrieved July 30, 2011 from http://www.betanews. com/article/How-Many-Users-Does-Second-Life-Really-Have/1178573043

Galusha, J. (1997). Barriers to Learning in Distance Education. University of Southern Mississippi. Retrieved September 26, 2011 from http://www.infrastruction.com/barriers.htm

Gartner Inc. (2008, May 28). Gartner Identifies Top Ten Disruptive Technologies for 2008 to 2012. Retrieved July 20, 2011 from http://www.gartner.com/it/page. jsp?id $=681107$

Gordon, K. (2011, February 2). MixAR: World's First 3D Augmented Reality Editor for iPhone. Retrieved July 22, 2011 from http://www.psfk.com/2011/02/mixarworlds-first-3d-augmented-reality-editor- 
for-iphone.html

Grabham, D. (2009). 8 Awesome Augmented Reality Apps for iPhone. Tech Radar. Retrieved July 23, 2010 from http://www. techradar.com/news/phone-and-communications/mobile-phones/8-awesome-augmented-reality-apps-for-iphone-639263

Hamilton, K. (2011). Retrieved July 19, 2011, from the Augmented Reality in Education Wiki: http://wik.ed.uiuc.edu/index.php/ Augmented_Reality_in_Education

Hamilton, K. \& Olenewa, J. (May, 2010). Augmented reality in education [PowerPoint slides]. Retrieved from Lecture Notes Online Web site: http://www.authorstream. com/Presentation/k3hamilton-478823-augmented-reality-in-education/

Hampp, A. (2009). Marketers Hop on Augmented Reality Bandwagon to Promote 'Avatar'. Retrieved November 28, 2009, from http://adage.com/madisonandvine/ article?article $\mathrm{id}=140661$

Handheld Augmented Reality Project (HARP) \& Alien Contact! Overview (n.d.). Retrieved July 22, 2010 from http://isites. harvard.edu/fs/docs/icb.topic135310.files/ AlienContactOverview012907.pdf

Höllerer, T. H., \& Feiner, S. K. (2004). Mobile Augmented Reality. In H. A. Karimi, \& A. Hammad (Eds.), Telegeoinformatics: Location-Based Computing and Services, (pp. 392-421). CRC Press.

Hughes, C. E., Stapleton, C. B., Hughes, D. E., \& Smith, E. M. (2005, November/December). Mixed reality in education, entertainment, and training. IEEE Computer Graphics and Applications, 24-30.

Ivan Sutherland Biography | World of Computer Science Biography Retrieved November 23, 2009 website: http://www.bookrags. com/biography/ivan-sutherland-wcs/.

Juniper Research (2011). Mobile Augmented Reality. Retrieved July 20, 2011 from http://juniperresearch.com/reports/mobile_ augmented_reality
Kato, H., \& Billinghurst, M. (1999). Marker tracking and hmd calibration for a videobased augmented reality conferencing system. The 2nd IEEE and ACM International Workshop on Augmented reality. IEEE.

Kaufmann, H. (2003). Collaborative augmented reality in education. Proceedings of Imagina 2003 conference, 1-4.

Kaufmann, H., \& Dünser, A. (2007). Summary of usability evaluations of an educational augmented reality application. Lecture Notes in Computer Science, 4563, 660-669.

Kaufmann, H., \& Schmalstieg, D. (2003). Mathematics and geometry education with collaborative augmented reality. Computers \& Graphics, 27, 339- 345.

Kerawalla, L., Luckin, R., Selijefot, S., \& Woolard, A. (2006). Making it real: Exploring the potential of augmented reality for teaching primary school science. Virtual Reality, 10(3-4), 163-174.

Klopfer, E., \& Squire, K. (2008). Environmental Detectives - the development of an augmented reality platform for environmental simulations. Educational Technology Research and Development , 56(2), 203-228.

Klopfer, E., \& Yoon, S. (2004). Developing games and simulations for today and tomorrow's tech savvy youth. TechTrends, 49(3), 41-49.

Lewis, E. (2005). Eye Toy: Play 2. Retrieved July 23, 2010 from http://ps2.ign.com/articles/ 641/641468p1.html

Liarokapis, F., Mourkoussis, N., White, M., Darcy, J., Sifniotis, M., Petridis, P., et al. (2004). Web 3D and augmented reality to support engineering education. World Transactions on Engineering and Technology Education, 3(1), 11-14.

Liarokapis, F., Petridis, P., Lister, P., and White, M. (2002). Multimedia Augmented Reality Interface for E-learning (MARIE). World Transactions on Engineering and Technology Education 1(2), 173-176. 
Liu, D., Jenkins, S. A., Sanderson, P. M., Fabian, P., \& Russell, W. J. (2010, April). Monitoring with head-mounted displays in general anesthesia: A clinical evaluation in the operating room. Society for Technology in Anesthesia, 110(4), 1032-1038.

Ludwig, C., \& Reimann, C. (2005). Augmented reality: Information at focus. Cooperative Computing \& Communication Laboratory (Volume 4. No. 1). Universität Paderborn.

Metaio. (2011). Mobile SDK. Retrieved July 21, 2011 from http://www.metaio.com/ software/mobile-sdk/

Milgram, P. \& Kishino, F. (1994). A taxonomy of mixed reality visual displays. IEICE Transactions on Information Systems, 77(12). Retrieved July 24, 2010 from http:// etclab.mie.utoronto.ca/people/paul_dir/IEICE94/ieice.html

Milgram, P., Takemura, H., Utsumi, A., \& Kishino, F. (1994). Augmented reality: A class of displays on the reality-virtuality continuum. Telemanipulator and Telepresence Technologies, 2351, 282-292.

Phan, V. T., \& Choo, S. (2010, August). Interior design in augmented reality in environment. International Journal of Computer Applications, 5(5), 16-21.

Raju (2009). 15 Stunning Augmented Reality Apps for iPhone. Technically Personal. Retrieved July 23, 2010 from http://techpp. com/2009/10/21/15-stunning-augmentedreality-iphone-apps/

Raskar, R., Welch, G., \& Fuchs, H. (1998). Spatially Augmented Reality. First International Workshop on Augmented Reality, pp. 1-7.

Rosenberg, L. B. (1993). The use of virtual fixtures to enhance operator performance in time delayed teleoperation. Retrieved July 21, 2011 from http://www.dtic.mil/cgi-bin/ GetTRDoc? Location $=\mathrm{U} 2 \&$ doc $=$ GetTRD oc.pdf \&AD=ADA296363

Samset, E., Schmalstieg, D., Vander Sloten, J., Freudenthal, A., Declerck, J., Casciaro, S.,
Rideng, Ø., \& Gersak, B. (2008) Augmented Reality in Surgical Procedures. In: Proc. SPIE Vol. 68.6.

Saenz, S. (2010, January 11). Augmented Reality To Help Military Mechanics Fix Vehicles (Video). Retrieved July 20, 2011 from http://singularityhub.com/2010/01/11/augmented-reality-to-help-military-mechanics-fix-vehicles-video/

Schmalstieg, D. (2001). An introduction to augmented reality [PowerPoint slides]. Retrieved from Lecture Notes Online Web site: http:// www.iswc.ethz.ch/events/tutorials/slides schmalstieg.pdf

Shelton, B. E., \& Hedley, N. R. (2002). Using augmented reality for teaching earth-sun relationship to undergraduate geography students. The First IEEE International Augmented Reality Toolkit Workshop (pp. 1-8). Darmstadt, Germany: IEEE.

Sielhorst, T., Feuerstein, M., \& Navab, N. (2008, December). Advanced medical displays: A literature review of augment reality . Journal of Display Display Technology, 4(4), 451-467.

Sielhorst, T., Obst, T., Burgkart, R., Riener, R., \& Navab, N. (2004). An augmented reality delivery simulator for medical training. In International Workshop on Augmented Environments for Medical Imaging - MICCAI Satellite Workshop (pp. 11-20). AMIARCS.

Sisodiaa, A., Bayerb, M., Townley-Smith, P., Nash, B., Little, J., Casarly, W., Gupta, A. (May, 2007). Advanced helmet mounted display (AHMD). SPIE 6557: Head- and Helmet-Mounted Displays XII: Design and Applications. Orlando, FL. doi:10.1117/12.723765

Steinkuehler, C., and Williams, D. (2006). Where everybody knows your (screen) name: Online games as "third places." Journal of Computer-Mediated Communication, 11(4), article 1. http://jcmc. indiana.edu/vol11/issue4/steinkuehler.html 
Thomas, B., Close, B., Donoghue, J., Squires, J., Bondi, P. D., \& Piekarski, W. (2001). First person indoor/outdoor augmented reality application: ARquake. Personal and Ubiquitous Computing, 6, 75-86.

Ubiquitous Learning. (2009). EduTech Wiki. Retrieved July 25, 2010 from http://edutechwiki.unige.ch/en/Ubiquitous_learning

Diakopoulos, N., Kivran-Swaine, F., Naaman, M. (2011). Playable data: Characterizing the design space of game-y infographics. CHI 2011, Vancouver, BC, Canada.

Webster, Andrew. (May 22, 2009). AR.Drone coming to Android, gets new multiplayer games. Arstechnica.com. Retrieved July 30, 2011 from http://arstechnica.com/gaming/news/2011/06/ardrone-coming-to-android-gets-new-multiplayer-games.ars

Wikitude (n.d.). Developer: Getting Started. Retrieved July 21, 2011 from http://www. wikitude.com/en/developer/getting-started

Yuen, S. C. -Y. (2010, November 19). 3D Augmented Reality Books. Retrieved July 21, 2011 from http://steveyuen.org/ blog/?p=754

Yuen, S. C. -Y. (2011, February 19). Augmented Reality Helicopter. Retrieved July 21, 2011 from http://steveyuen.org/ blog/?p=1082

Yuen, S. C. -Y. (2011, February 25). Ford of Britain Launched an AR Campaign. Retrieved July 21, 2011 from http://steveyuen. org/blog/?p=1124

Yuen, S. C. -Y. (2011, July 14). Daqri. Retrieved July 21, 2011 from http://steveyuen. org/blog/?p=2368

Zhou, F., Duh, H.-L., \& Billinghurst, M. (2008). Trends in augmented reality traching, interaction and display: A review of ten years in ISMAR. Mixed and Augmented Reality, ISMAR 7th IEE/ACM International Symposium pp. 193-202. Cambridge: IEEE.

Zhu, W., Owen, C., Li, H., \& Lee, J.-H. (2004). Personalized in-store e-commerce with PromoPad: an augmented reality shopping assistant. Electronic Journal for E-commerce Tools and Applications, 1(3), 1-19. 


\section{Contact the Authors}

Steve Chi-Yin Yuen, Ph.D.

National Kaohsiung Normal University

Email: scyyuen@gmail.com

\section{Gallayanee Yaoyuneyong, Ph.D.}

The University of Southern Mississippi

Email: Gallayanee.Yaoyuneyong@usm.edu

\section{Erik Johnson}

The University of Southern Mississippi

Email: yishnir@gmail.com 